\title{
Avaliação e gestão da autossustentabilidade organizacional: estudo de caso em Faculdade Particular de Fortaleza-Ceará
}

Marcos Antonio Martins Lima

Universidade Federal do Ceará

Antonio Cabral Neto

Universidade Federal do Rio Grande do Norte

\section{Resumo}

$\bigcirc$ presente artigo objetiva discutir sobre a avaliação e a gestão da autossustentabilidade organizacional, baseada nas suas estruturas essenciais junto a uma Instituição de Ensino Superior (IES) privada de Fortaleza-Ceará. Trata-se de um estudo de caso que é apresentado com base na estratégia metodológica quadripolar tendo, como categorias epistemológicas e teóricas, a avaliação e a gestão nos campos da Educação e da Administração. Para tanto, utilizou-se de um questionário com questões objetivas e abertas. Na análise dos dados objetivos, foram utilizadas técnicas estatísticas com a aplicação do programa SPSS, enquanto na análise de dados qualitativos foi aplicado o 240 software Atlas.ti7.

Palavras-chave: Autossustentabilidade organizacional. Gestão educacional. Avaliação educacional.

\section{Evaluation and management of organizational self-sustainability: a study case at a Private College in Fortaleza, state of Ceará}

\section{Abstract}

This paper aims to discuss the evaluation and management of organizational self-sustainability, based on its essential structures in a private Higher Education Institution (HEI) in Fortaleza-Ceará. It is a study case presented within the quadripolar methodological strategy, that has the evaluation and management in the fields of Education and Administration as epistemological and theoretical categories. For this purpose, we used a questionnaire with objective and open questions. We applied the SPSS program in the analysis of the objective data statistical techniques, and the Atlas.ti7 software in the analysis of qualitative data.

Palabras clave: Programa de educación para la salud. Educación para la salud. Higiene. 


\section{Evaluación y gestión de la autosostenibilidad organizacional: estudio de caso en una Faculdad Particular de Fortaleza-CE}

\section{Resumen}

Este estudio tiene por objetivo discutir sobre la evaluación y la gestión de autosostenibilidad organizacional, basada en sus estructuras esenciales junto a una institución de enseñanza superior de Fortaleza, ciudad brasileña ubicada en el estado de Ceará. Se trata de un estudio de caso presentado según la estrategia metodológica cuadripolar, teniendo como categorías epistemológicas y teóricas la evaluación y la gestión en los campos de la Educación y de la Administración. Para ello recurrió a un cuestionario con preguntas objetivas y abiertas. En el análisis de los datos objetivos, se utilizaron técnicas estadísticas con el uso del aplicativo SPSS; en cuanto al análisis de los datos cualitativos, se recurrió al programa Atlas.ti7.

Palabras clave: Autosostenibilidad organizacional. Gestión educacional. Evaluación educacional.

\section{Introdução}

A avaliação e a gestão nos campos da Educação e da Administração, como temas complexos, são aqui compreendidos como categorias teóricas que requerem diferentes nuanças de tratamento, tocando as estruturas epistemológica, histórica, social, econômica, política e organizacional.

A problematização é o contexto ambiental em que se inserem os problemas da pesquisa. Materializa-se, portanto, na possibilidade de apresentação de problemas a serem discutidos, refletidos, minimizados ou até solucionados.

espírito científico proíbe que tenhamos uma opinião sobre questões que não compreendemos, sobre questões que não sabemos formular com clareza. Em primeiro lugar, é preciso saber formular problemas. E, digam o que disserem, na vida científica os problemas não se formulam de modo espontâneo. É justamente esse 'sentido do problema' que caracteriza o verdadeiro espírito científico. Para o espírito científico, todo conhecimento é resposta a uma pergunta. Se não há pergunta, não pode haver conhecimento científico. Nada é evidente. Nada é gratuito. Tudo é construído (BACHELARD, 1996, p. 18). 
Avaliação e gestão da autossustentabilidade organizacional: estudo de caso em Faculdade Particular de Fortaleza-Ceará

A problemática desta pesquisa está representada nos seguintes questionamentos epistemológicos e teóricos: as propostas de avaliação estrutural-sistêmica no campo da Educação, e das teorias administrativas da dependência de recursos e da visão baseada em recursos (VBR) são viáveis para fundamentação do conceito de autossustentabilidade organizacional em Instituições de Ensino Superior (IES) privadas? $\bigcirc$ conceito de tríade da autossustentabilidade organizacional (colaboradores; alunos; e econômico-financeiro) pode ser aplicado na avaliação e na gestão de IES particular de FortalezaCeará que oferta cursos de graduação presencial em Administração e em Pedagogia?

Os estudos sobre a avaliação e a gestão na educação superior têm buscado como alvo predominante as instituições públicas. As instituições privadas, porém, com o seu crescimento em número de instituições, de cursos e de matrículas, precisam ser pesquisadas mais amiúde, com a ênfase na qualidade educacional que deve ser demonstrada para a sociedade e para o País.

A história da expansão do ensino superior atingiu patamares nunca antes vistos com o advento do século XX e com a industrialização decorrente do avanço do modo de produção capitalista. No Brasil, esse fator de crescimento 242 econômico, então atingindo a era da globalização, foi o principal motivador da continuidade da expansão do ensino superior. Após a criação da primeira faculdade isolada de ensino superior em 1810 e a primeira universidade em 1912, o primeiro e significativo expansionismo da Educação superior do Brasil aconteceu no período de 1912 a 1915, com um desordenado crescimento do número de instituições privadas, viabilizado pela Reforma Rivadávia Corrêa, logo contida com outra reforma, a de Carlos Maximiliano, em 1915. A "Era Vargas" e a Revolução de 1930 marcaram um novo momento de expansão de universidades e faculdades isoladas, baseado no suporte jurídico-educacional da Reforma Francisco Campos, de 1931. Essa fase foi marcada pela consolidação do ensino superior privado no Brasil. "Foi nesse cenário maior de disputa pelo controle do ensino superior entre elites laicas e católicas, sob uma moldura legal centralizadora - como a legislação de 1931 - que se consolidou o ensino superior privado no País" (SAMPAIO, 2000, p. 46).

Essa fase expansionista perdurou até 1961, embora em 1950 tenha sido adotada a estratégia de federalização de faculdades particulares isoladas, ampliando o número de universidades públicas no País. Com a Lei $n^{\circ}$ 4.024, de 20 de dezembro de 1961, reconhecendo a incapacidade 
de absorção da demanda crescente, o governo estimulou uma nova fase de expansão privada de instituições isoladas de ensino superior a partir de 1965, sendo o ano de 1968 marcado como o primeiro boom das IES privadas isoladas (VAHL, 1980, p. 38), chegando à equiparação histórica de 50\% das matrículas entre as instituições públicas e privadas em 1970.

Nos anos de 1974 e 1977, o governo aplicou uma política de contenção para frear a expansão privada de IES. Mesmo assim, o movimento expansionista continuou a sua caminhada pelo Brasil com a ditadura militar e, mais precisamente, com o advento da "Nova República", em 1985, e uma situação econômica de desemprego crescente. Verificou-se um movimento de retração no grau de expansão no período de 1980 a 1990, fenômeno que Sampaio (2000) assim analisa, embora, nos anos seguintes, se tenha retomado um novo momento de alto crescimento do setor privado na educação superior. Essa tendência de ampliação do ensino superior vai se configurando nos anos subsequentes (1999-2010), marcada inclusive, pela maior atuação do setor privado do que do setor público. Essa situação foi bem ilustrada por Fávero e Sguissardi (2012, p. 76) quando constatam que "[...] no período referido o crescimento das instituições privadas foi de $252 \%$ enquanto o aumento das públicas ficou em 44\%".

Essa realiade vem se consolidando no país, considerando que segundo dados do Instituto Nacional de Estudos e Pesquisas Educacionais Anísio Teixeira (Inep/BRASIL, 2015), sobre os resultados do Censo da Educação Superior de 2013, que são os últimos disponibilizados pelo Ministério da Educação, - o Brasil possui 7,3 milhões de universitários, 5.373.450 (73,60\%) estudam em instituições particulares e 1.932.527 (26,40\%), em pública s. Na quantidade de instituições, são 2.391 instituições de ensino superior, sendo $2.090(87,41 \%)$ particulares e 301 instituições públicas $(12,59 \%)$.Vê-se um campo de relevância para pesquisas sobre essa maioria crescente de matrículas e de instituições privadas de ensino superior no Brasil.

Esses números representam resultados concretos da aplicação de políticas educacionais neoliberais não só no Brasil, mas também em toda a América Latina e Caribe e consolidada na década de 1990, em decorrência de financiamento e assessoramento do Banco Mundial, que passou a tratar a Educação como um serviço, continuando a valorizar a sua marcante execução por instituições privadas, em detrimento das instituições públicas em minoria (CABRAL NETO; RODRIGUEZ, 2007). 
Avaliação e gestão da autossustentabilidade organizacional: estudo de caso em Faculdade Particular de Fortaleza-Ceará

Pode-se observar, portanto, que a atual política de expansão adotada mantém algumas das características, ao mesmo tempo em que incentiva, cada vez mais, o crescimento do ensino particular, ampliando o processo de privatização da educação (BARBALHO, 2007, p. 77).

Desse modo, a avaliação e a gestão tornam-se fatores-chave para a busca de níveis de qualidade educacional e de sustentabilidade organizacional nas IES privadas, com a necessária autonomia para cumprimento do seu papel essencial de construção e multiplicação de conhecimentos e competências capazes de contribuir para o desenvolvimento científico e humano, nos níveis individual, grupal, local, regional, nacional e internacional.

objetivo central deste artigo é discutir sobre a gestão da autossustentabilidade organizacional, baseada nas suas estruturas essenciais junto a uma Instituição de Ensino Superior (IES) privada de Fortaleza-Ceará.

O enfoque na avaliação e na gestão da autossustentabilidade organizacional de cursos presenciais de graduação em Administração e Pedagogia, voltados para modelos práticos e aplicáveis (polo morfológico) em instituições de ensino superior privada instalada em Fortaleza-Ceará, possibilita o desafio de explorar, sob uma exigência de maior fundamentação epistemológica e teórica, a qualidade educacional nesta organização, tomando por base epistemológica o estruturalismo e o sistemismo; e por base teórica e morfológica a integração entre as teorias organizacionais da dependência de recursos e da visão baseada em recursos (VBR), e a teoria da avaliação estrutural-sistêmica de Lima (2008).

A sobrevivência e o desenvolvimento de uma instituição educativa dependem da sua qualidade educacional conquistada e reconhecida como satisfatória a partir da diversidade de interesses dos seus diferentes atores ou "stakeholders". A sustentabilidade organizacional nos planos individual e grupal dos educandos, do corpo docente e da própria organização educacional torna-se viável a partir de uma autocrítica a respeito da sua situação passada e presente, buscando uma transformação satisfatória em relação a uma circunstância pretendida. Com esse desafio, a avaliação e a gestão educacional desempenham forte papel viabilizador, ampliando e facilitando o aprimoramento da educação superior e das suas organizações condutoras. 
Os estudos em ciências sociais e humanas, nos quais se inserem as ciências da Educação e da Administração, necessitam, em seu desenvolvimento, de melhor consciência metodológica que permita uma maior exploração do seu objeto científico, mesmo que isso seja um processo em construção permanente em sua natureza humana e política.

$\bigcirc$ presente artigo, produto do trabalho de estágio pós-doutoral, corresponde a uma proposta de investigação com aplicação do espaço metodológico quadripolar. Segundo De Bruyne, Herman e De Schoutheete (1977), o campo científico pode ser estruturado a partir de uma metodologia geral em 4 (quatro) polos distintos, mas que se complementam e interagem como eixos de uma mesma prática metodológica: os polos epistemológico, teórico, morfológico e técnico.

Segundo De Bruyne, Herman e De Schoutheete (1977), o polo epistemológico corresponde ao eixo das indagações e da problemática, dos fundamentos de base do conhecimento. $O$ eixo teórico é o campo dos conceitos, das abordagens teóricas a serem exploradas ou adotadas como referenciais teóricos para a pesquisa. O polo morfológico registra os modelos conceituais ou operacionais resultantes das formulações teóricas e epistemológicas. E, finalmente, o polo técnico é o campo da concretização da pesquisa no lócus do objeto, com o levantamento e análise de dados, buscando respostas para os problemas e questões geradas no empreendimento.

Trata-se de uma pesquisa quali-quantitativa, aplicada em um estudo de caso junto a vários "stakeholders" de uma IES privada de Fortaleza-Ceará (discentes, docentes, dirigentes, gestores, técnicos-administrativos, terceirizados e estagiários) com o suporte dos softwares SPSS versão 21.0 para Windows (Statistical Package for the Social Sciences) e Atlas.ti7 versão 7.1 para Windows (Computer - Assisted Qualitive Data Analysis Software-CAQDAS).

\section{Polo epistemológico}

A epistemologia de Gaston Bachelard (1884-1962) preenche o campo epistemológico do presente artigo, contribuindo para a conquista do método contemporâneo, ao observar, na relação de conhecimento inacabado e provisório, uma interação constante e complementar do sujeito com o objeto do conhecimento. 
Desde que o homem filosofa, indaga sobre a essência do conhecimento, e essa trajetória revela um processo de concepção de erros. Segundo Bachelard (1968), o espírito científico funda-se sobre a consciência de seus erros. Esse pensador defende uma filosofia crítica, que procura reformular os conceitos científicos e filosóficos da ciência, e, ainda, uma filosofia anti empirista, racionalista, integrada à ciência, renovadora e desprovida de qualquer ortodoxia, na qual as ciências devem produzir as suas normas de verdade e o emprego de métodos múltiplos capazes de considerar a complexidade do conjunto de relações que permeiam o objeto científico.

$\bigcirc$ termo sustentável provém do latim sustentare (sustentar, defender, favorecer, apoiar, conservar e cuidar), acrescente-se o objetivo da sustentabilidade em tornar algo duradouro, perene e longevo, buscando sempre o longo prazo.

A origem do termo sustentabilidade sinaliza-a como sendo a capacidade de sobreviver, conservar, suportar, manter, amparar, impedir que algo decline. Ainda é a capacidade aplicada a fim de fornecer ou garantir o necessário para a sobrevivência no planeta, em uma sociedade ou em uma 246 e potencialmente captáveis.

Por ser um constructo polissêmico, o termo sustentabilidade não apresenta um entendimento único e de aplicação universal, mas é aceito como aplicado a diversas dimensões integradas segundo as conjunturas econômica, social e ambiental.

Quando a organização dirige a reflexão da sustentabilidade para si mesma, sem perder de vista suas relações com o ambiente externo, passa a aplicar o conceito aqui proposto de autossustentabilidade organizacional. Assim como o termo sustentabilidade, o verbete autossustentabilidade refere-se à capacidade de autossustentar-se, como a qualidade de poder sustentar a si mesmo.

Assim o termo autossustentabilidade organizacional representa a capacidade de uma organização gerar, com recursos próprios, a sua sustentabilidade, tornando-a longeva na sua sobrevivência ao ambiente (interno e externo) e nas suas interações com esse mesmo ambiente.

Assim, pode-se definir a autossustentabilidade organizacional aplicada a Educação, como a capacidade própria de alcançar a excelência em 
seu segmento de atuação e na sociedade que participa, fortalecendo-se em termos econômico-financeiros, de alunos e de colaboradores, visando a sua longevidade existencial e interagindo, permanentemente, com seu ambiente externo.

As questões-problema colocadas na pesquisa consideram a viabilidade de aplicação das propostas teóricas de avaliação estrutural-sistêmica (LIMA, 2008) no campo da Educação, e das teorias administrativas da dependência de recursos (ALDRICH; PFEFFER, 1976; PFEFFER; SALANCIK, 1978) e da Visão Baseada em Recursos (VBR) (HITT; IRELAND; HOSKISSON, 2008) no estudo sobre a autossustentabilidade organizacional em IES privada. Ademais, busca a verificação da aplicação do conceito de tríade da autossustentabilidade organizacional (alunos; colaboradores; e econômico-financeiro) na avaliação e na gestão de uma IES privada de Fortaleza-Ceará que oferta cursos de graduação presencial em Administração e em Pedagogia.

O polo seguinte visa explorar essas categorias presentes na problemática e fundamentar as alternativas teóricas e conceituais a serem adotadas para solucionar as questões norteadoras da pesquisa.

\section{Polo teórico}

propósito de avaliar a gestão da autossustentabilidade organizacional no ambiente educacional superior e presente em uma faculdade privada de Fortaleza-Ceará tem como foco principal a investigação da qualidade educacional específica dessa organização.

Embora seja um conceito polissêmico no campo da Educação, a "qualidade educacional", a ser aqui considerada, está sintonizada com o conceito adotado por Lima (2008), ou seja, como sendo uma intencionalidade em promover uma educação que realmente contribua para o desenvolvimento individual, grupal e da sociedade de educandos, bem como para o desenvolvimento das instituições e das políticas educacionais, nos níveis científico, tecnológico, econômico, social e político com igualdade de oportunidades para todos e autonomia de atuação para as instituições.

Outro importante conceito a ser enfocado é o de autossustentabilidade organizacional, como sendo a capacidade própria da organização educativa de alcançar a qualidade educacional, fortalecendo-se em termos 
econômico-financeiros, de resultados efetivos com os seus alunos, e de satisfação, competências e desempenho com os seus colaboradores, visando a sua longevidade existencial e interagindo, permanentemente, com seu ambiente externo.

A integração entre as teorias administrativas da dependência de recursos e da visão baseada em recursos (VBR), é fundamentada na abordagem teórica; e a teoria da avaliação estrutural-sistêmica de Lima (2008), na fundamentação epistemológica e morfológica.

\section{Teoria da Avaliação Estrutural-sistêmica}

Historicamente, o termo "estrutura" tem sua origem no latim structura que, por sua vez, vem do verbo struere que significa construir. Heráclito (540 a.C. -480 a.C.), nos primórdios da filosofia, já definia o logos como uma unidade estrutural que domina o fluxo ininterrupto do devir e o torna inteligível. Nos séculos XVII e XVIIII, o sentido do termo modifica-se e amplia-se do aspecto arquitetural, assumindo o sentido da descrição da maneira como as partes integrantes de um ser concreto organizam-se numa totalidade. Apesar de ser aplicada a várias áreas do conhecimento e a partir de variados conceitos, uma das importantes intenções do estruturalismo é mapear a totalidade das estruturas do objeto ou processo em estudo, obtendo o seu conjunto de relações determinantes, comportando as leis que produzem e buscam o equilíbrio ou feedback dos seus sistemas componentes.

Estrutura e sistema são termos que, por vezes, são adotados como sinônimos mesmo no campo científico. Aqui, estruturas são formadas por diversos sistemas componentes e interligados, imprimindo dinâmica à estrutura. $\bigcirc$ termo sistema vem do latim tardio e do grego systema, de synistanai: juntar. A noção de sistema, além da origem grega, enquanto reunir, ordenar e coligir, corresponde ao resultado de uma atividade sistematizadora. Sistematizar é, pois, dar, intencionalmente, unidade à multiplicidade.

Mas sistema e estrutura são conceitos diferentes. Embora ambos sejam formados por um conjunto de elementos, a estrutura implica a própria textura da realidade, indicando a forma como as coisas se entrelaçam, algumas vezes independentemente do homem, outras vezes envolvendo o homem, como no caso das estruturas organizacionais. $\bigcirc$ sistema, por sua vez, implica uma 
ordem que o homem impõe à realidade, ou seja, é "[...] um arranjo lógico da realidade, com a identificação de fins comuns, para os quais concorrem harmonicamente os componentes de determinada estrutura" (SOUZA, 2001, p. 27).

A grande contribuição do "sistemismo" aqui não é a inter-relação dos elementos componentes da estrutura, pois esse aspecto é bastante explorado pelo estruturalismo, mas a sua capacidade de constante retroação, feedback ou autorregulação, não em relação ao ambiente puramente interno da estrutura, mas, especialmente, ao seu ambiente exterior e as variáveis exógenas influenciadoras.

A proposta de integração entre estruturalismo e "sistemismo" para uma avaliação estrutural-sistêmica, visa permitir o estudo das estruturas do objeto científico de forma sistematizada e relacionada a um contexto aberto ao seu sistema, que pode representar a própria totalidade resultante do estudo das estruturas e que também configura a existência do objeto.

As estruturas essenciais de avaliação constituem os elementos principais que compõem um "objeto multidimensional a ser avaliado", dispostos de forma sincrônica e diacrônica, e que representam a textura da realidade que envolve e absorve um "objeto a ser avaliado" (LIMA, 2008). Uma estrutura essencial é um conjunto de sistemas integrados por um processo de autorregulação ou feedback, porém que não abstrai o caráter não teleológico com possibilidade de presença na própria estrutura ou nas variáveis exógenas ou endógenas do seu ambiente, inseridas aí as variáveis sociais, psicológicas, políticas, éticas e ideológicas.

Com base nasideias apresentadas para um estruturalismo-sistêmico (LIMA, 2008), propõe-se uma avaliação estrutural-sistêmica da autossustentabilidade de uma organização, como sendo um ato científico-humano consciente de forma a ampliar o conhecimento do valor sobre a autossustentabilidade organizacional, a partir da reflexão e percepção, do ato de planejar, da decisão e da ação correspondente, visando transformar, sistematicamente, o atual nível de desempenho da sustentabilidade da organização educativa em um novo e melhor nível de desempenho e que também promova, processualmente, uma transformação no desenvolvimento integral da própria organização.

A avaliação estrutural-sistêmica é plural e múltipla, pois absorve aspectos do ambiente interno e externo, mas também é consciente da sua limitação 
avaliativa, pois toda avaliação é inacabada. Através, porém, do mapeamento das estruturas essenciais de autossustentabilidade organizacional, proporcionado pelos momentos de pensamento e planejamento, é possível identificar sistemas componentes dessas estruturas, construir um projeto com abordagem qualitativa-quantitativa, e aplicar a avaliação em nível estrutural-sistêmico, conforme ilustra a Figura 1, a seguir.

Figura 1

\section{Avaliação Estrutural-sistêmica}

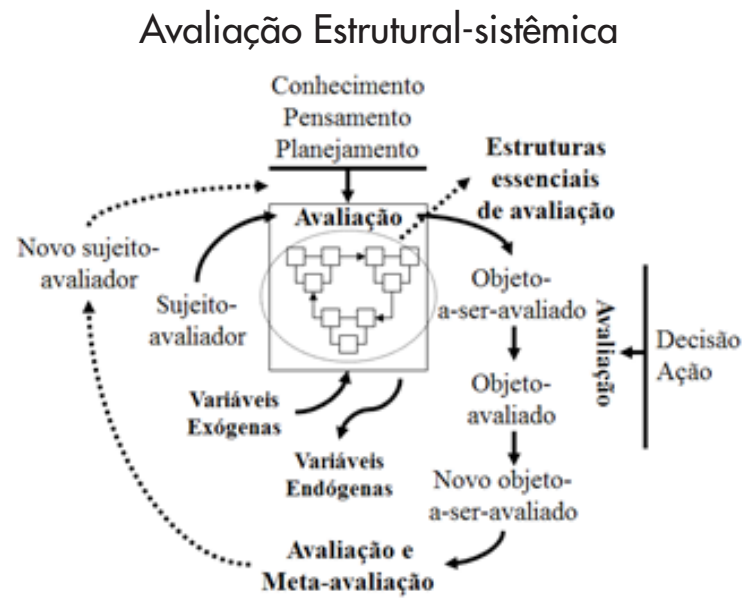

Fonte | Lima (2008)

contexto abrange os ambientes interno e externo influenciadores na avaliação das estruturas de autossustentabilidade organizacional, pela identificação de variáveis exógenas e endógenas envoltas em matizes sociais, ambientais, políticos, econômicos e históricos. Dessa forma, as variáveis de contexto buscam, embora possam ter perfis qualitativos ou quantitativos, maior objetividade ao estudo da autossustentabilidade em avaliação.

No estudo das estratégias visando à autossustentabilidade organizacional, muitas são as propostas teóricas, mas aqui se busca a teoria da dependência de recursos e a teoria da visão baseada em recursos (VBR) como referenciais, visto que se complementam quanto à gestão de recursos nos ambientes externo e interno, respectivamente. 


\section{Teoria de Dependência de Recursos}

O termo gestão vem do latim gestione: ato de gerenciar. Pode-se considerar que gestão é o ato de gerir um empreendimento, uma organização, um projeto, uma unidade interna de uma organização ou uma equipe de pessoas. Gestão é uma macroestrutura organizacional essencial formada por vários sistemas integrados de planejamento, organização, direção, execução e avaliação.

Gerir, no campo da Administração, é o processo que visa conseguir a melhor relação entre recursos, capacidades e competências, visando ao alcance de vantagens competitivas e o consequente retorno acima da média dos seus concorrentes (HITT; IRELAND; HOSKISSON, 2008).

A importância da gestão no campo da Educação emerge, com maior ênfase, a partir das crises e da reestruturação do sistema capitalista na segunda metade de Século XX, caracterizada por recessão econômica, altas taxas de inflação, baixo índice de crescimento e excessivos gastos sociais, e levando-se a adoção de modelo de gestão baseado nos conceitos da Administração Capitalista.

Porém, gerir, no campo da Educação, é o processo que visa a

[...] dinâmica do sistema de ensino como um todo e de coordenação das escolas em específico, afinado com as diretrizes e políticas educacionais públicas, para a implementação das políticas educacionais e projetos pedagógicos das escolas, compromissado com os princípios da democracia e com métodos que organizem e criem condições para um ambiente educacional autônomo (soluções próprias, no âmbito de suas competências) de participação e compartilhamento (tomada conjunta de decisões e efetivação de resultados), autocontrole (acompanhamento e avaliação com retorno de informações) e transparência (demonstração pública de seus processos e resultados) (LUCK, 2006, p. 35-36).

A tríade da autossustentabilidade organizacional é função das suas 3 (três) estruturas essenciais: (1) alunos; (2) colaboradores; e (3) econômico-financeiro e sua necessária integração estrutural-sistêmica.

A gestão da tríade da autossustentabilidade organizacional é o processo que visa contribuir para a excelência da organização educativa no atingimento da sua missão e para o fortalecimento, contínuo, das suas 
estruturas essenciais (alunos; colaboradores; e econômico-financeiro) visando a sua qualidade educacional e a sua longevidade existencial e interagindo, permanentemente, com seu ambiente externo.

A teoria da dependência de recursos (resource dependence teory) surge na década de 1970 e tem como premissa básica considerar a influência do ambiente externo na organização, sendo que a correta gestão das interações com o ambiente externo é a chave para a sua sustentabilidade organizacional (ALDRICH; PFEFFER, 1976; PFEFFER; SALANCIK, 1978).

Assim, a teoria da dependência de recursos dá ênfase ao ambiente externo no estudo da estratégia organizacional e defende que todas as organizações apresentam dependência de algum elemento desse ambiente exterior, embora reconheça a importância do ambiente interno.

ambiente externo afeta as organizações pela oferta ou não de determinados recursos. Essa dependência externa precisa ser devidamente gerenciada pela organização com a sua adaptação às realidades ambientais e ao fluxo de recursos em troca com esse ambiente externo. Para obter recursos externos que não podem ser gerados internamente, as organizações devem realizar relações de troca com stakeholders no ambiente exterior. Para tanto, podem até modificar as suas estruturas e comportamentos para adquirir e manter os recursos humanos e materiais necessários.

A competência em obter e controlar seus recursos, e em lidar com as contingências do ambiente e com os seus stakeholders, torna-se decisiva para a autossustentabilidade organizacional.

Na teoria da dependência dos recursos, o ambiente é visto como um sistema integrado de organizações componentes, sendo que cada organização precisa interagir a fim de conservar a sua existência. Logo, a autossustentabilidade da organização, segundo a teoria da dependência dos recursos, é fortemente impactada pelo seu ambiente externo, e o alcance de desempenhos satisfatórios depende também da sua competência em interagir com esse ambiente exterior e obter os recursos tangíveis e intangíveis necessários.

Ao se considerar a tríade da autossustentabilidade como sendo recursos organizacionais essenciais, cabe à organização desenvolver a capacidade permanente para obter e captar recursos econômico-financeiros; capacitar, motivar e reconhecer o recurso colaboradores e, também, captar, satisfazer e desenvolver o recurso alunos. 


\section{Teoria da Visão Baseada em Recursos (VBR)}

Como a teoria da dependência dos recursos deu ênfase ao ambiente externo, na visão estrutural-sistêmica aqui empregada, não se pode abstrair o ambiente organizacional interno no estudo da autossustentabilidade organizacional.

A Visão Baseada em Recursos - VBR (Resource Based View: RBV) é uma outra proposta teórica sobre estratégia organizacional, porém, no caso de uma organização educacional, busca-se a qualidade educacional ou a excelência de serviços por meio de um modelo de desempenho com foco na avaliação e na gestão dos seus recursos e das suas capacidades internas.

Capacidades representam a combinação de diferentes recursos que permitem executar uma tarefa ou atividade de forma integrada. Existem capacitações quando os recursos são integrados, deliberadamente, para se executar uma tarefa ou um conjunto de tarefas específicas, as quais variam desde a seleção de recursos humanos até o marketing institucional (HITT; IRELAND; HOSKISSON, 2008).

Pode-se constatar que o objetivo central da teoria da visão baseada em recursos (VBR) é compreender a criação, a manutenção e a renovação da excelência de serviços ou qualidade educacional no que se refere aos recursos internos, garantindo a gestão dos retornos acima da média, por meio da avaliação da autossustentabilidade das suas capacidades (combinação de recursos) (HITT; IRELAND; HOSKISSON, 2008).

A teoria da dependência de recursos e a teoria da visão baseada em recursos podem ser perfeitamente integradas para a fundamentação da avaliação estrutural-sistêmica da autossustentabilidade de uma organização, pois ambas tratam da importância da gestão de recursos como dimensões, pilares ou estruturas fundamentais para a autossustentabilidade organizacional.

O polo seguinte tem o objetivo de traduzir esses conceitos teóricos, propostos para as categorias por meio de modelos viáveis de aplicação no polo técnico da pesquisa. 


\section{Polo morfológico}

modelo para a avaliação e a gestão da autossustentabilidade organizacional específica de uma Faculdade privadas deverá considerar a proposta teórica de avaliação estrutural-sistêmica de Lima (2008) e as teorias administrativas da dependência de recursos (ALDRICH; PFEFFER, 1976; PFEFFER; SALANCIK, 1978) e da visão baseada em recursos (VBR) (HITT; IRELAND; HOSKISSON, 2008) no estudo sobre a autossustentabilidade organizacional em IES particular.

Deve, ainda, em seu simulacro, considerar a aplicação do conceito de tríade da autossustentabilidade organizacional (alunos; colaboradores; e econômico-financeiro) na avaliação e na gestão de uma IES privada de Fortaleza-Ceará que oferta cursos de graduação presencial em Administração e em Pedagogia.

Assim, a avaliação da autossustentabilidade organizacional, conforme a Figura 2, a seguir, é um processo de apreciação crítica da organização educativa quanto a sua capacidade própria de chegar à excelência em seu segmento de atuação, ou seja, a sua qualidade educacional, analisando-a em termos de colaboradores (estagiários, terceirizados, técnicos, docentes e gestores); de alunos e sociedade (discentes, comunidade e sociedade do entorno); e no aspecto econômico-financeiro (relação receitas e despesas) que, de forma integrada, contribuam para a sua longevidade existencial.

Figura 2

Modelo de Avaliação e Gestão da Autossustentabilidade Organizacional

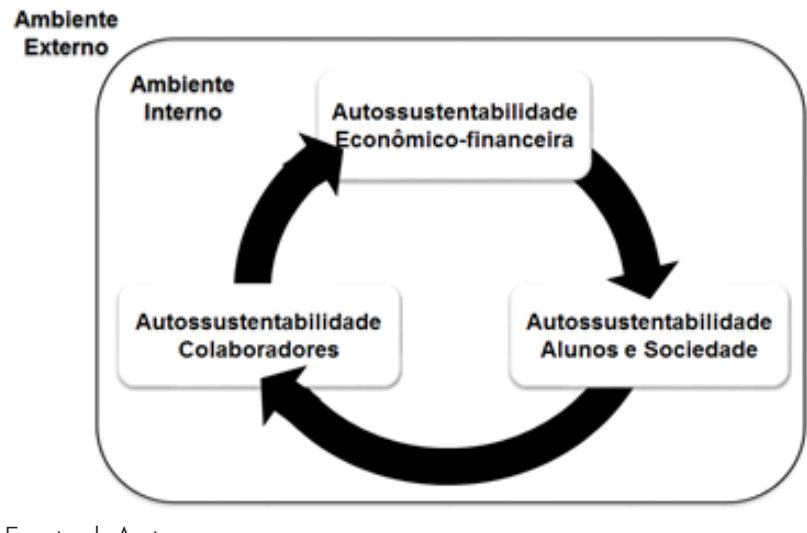

Fonte | Autores 
A avaliação da autossustentabilidade organizacional, além de reflexiva, deve ter grande amplitude coletiva. Por ser coletiva e abranger a participação ativa dos seus stakeholders, a avaliação da autossustentabilidade organizacional deve ser amplamente negociada internamente, promovendo acordos de avaliação, por meio da validação e implantação de indicadores de autossustentabilidade, norteados pelo mapeamento prévio de estruturas essenciais de avaliação e componentes da autossustentabilidade organizacional (alunos; colaboradores; e econômico-financeiro).

A gestão da autossustentabilidade organizacional também deve ser reflexiva, participativa e democrática. Seu modelo deve ser amplamente negociado internamente, por meio do acompanhamento de indicadores de autossustentabilidade, norteados pelo mapeamento prévio de estruturas essenciais de avaliação e componentes da autossustentabilidade organizacional (alunos; colaboradores; e econômico-financeiro).

Com a proposição do modelo, torna-se mister realizar o empreendimento da pesquisa no lócus de uma IES privada de Fortaleza-Ceará. Isso é a intenção do polo técnico seguinte.

\section{Polo técnico}

O polo técnico constitui o espaço de experimentação concreta do racionalismo aplicado empregado nos demais polos, concretizando a relação bachelardiana racionalismo-experiência ou abstrato-concreto-abstrato (BACHELARD, 1968).

\section{Ambiente organizacional da pesquisa}

A Instituição de Ensino Superior (IES) selecionada para o estudo de caso preenche as condições requeridas pela pesquisa, quais sejam, IES privada instalada em Fortaleza-Ceará, oferecendo os cursos de graduação presencial em Administração e em Pedagogia em pleno funcionamento, porém o estudo não teve a autorização institucional para a identificação da IES.

Fundada em 2002, sua missão institucional busca contribuir para o desenvolvimento do País e do Estado do Ceará, centrada na qualidade do 
Avaliação e gestão da autossustentabilidade organizacional: estudo de caso em Faculdade Particular de Fortaleza-Ceará

ensino superior, com base nas condições de trabalho e na preparação para seus colaboradores, e, também, na infraestrutura física, material e econômica.

Desde o início das suas atividades em 2004, tem conquistado espaço na educação superior em Fortaleza-Ceará, tomando como referência um conceito moderno de desenvolvimento local e regional, ofertando cursos de graduação, pós-graduação e extensão universitária para a formação profissional.

Os cursos de Pedagogia e Administração foram reconhecidos em 2012 , sendo o primeiro oferecido nos turnos da manhã e à noite e o segundo, no turno noturno.

\section{Procedimentos de pesquisa}

Trata-se aqui de uma pesquisa quali-quantitativa sobre a avaliação da gestão da autossustentabilidade organizacional, como estudo de caso em uma IES particular de Fortaleza-Ceará que oferta cursos de graduação presenciais em Administração e em Pedagogia.

Utilizou-se, como instrumento de levantamento de dados, um questio256 nário com questões objetivas e abertas.

As questões objetivas exploraram as estruturas essenciais: colaboradores (estagiários, terceirizados, técnicos, docentes e gestores); alunos (discentes); e econômico-financeira (recursos em forma de receitas e despesas), considerando-se a seguinte escala de respostas: 1 - Muito insatisfeito; 2 - Insatisfeito; 3 - Nem satisfeito, nem insatisfeito; 4 - Satisfeito; 5 - Muito satisfeito; 0 - Não sei responder.

Na análise de dados da parte quantitativa, foram utilizadas técnicas de estatística descritiva, teste T, Alfa de Cronbach e Correlação de Pearson com a utilização do programa Statistical Package for Social Sciences (SPSS) versão 21.0.

As questões qualitativas (abertas) compreendem justificativas apresentadas facultativamente pelos respondentes para cada estrutura essencial do conceito de autossustentabilidade: colaboradores; alunos; e econômico-financeira. 
Na análise de dados em sua parte qualitativa (questões abertas), foi aplicado o software Atlas.ti7 versão 7.1 (Computer - Assisted Qualitive Data Analysis Software-CAQDASI.

A equipe potencial (universo) da IES a ser envolvida na pesquisa foi dimensionada em: 1 diretor geral, 2 coordenadores de curso (Administração e Pedagogia), 18 docentes de Pedagogia, 27 docentes de Administração, 293 alunos de Pedagogia, 391 alunos de Administração, 53 técnicos-administrativos, 18 terceirizados e 10 estagiários.

A amostra retornada da pesquisa foi a seguinte: 1 diretor geral, 2 coordenadores de curso (Administração e Pedagogia), 8 docentes de Pedagogia, 8 docentes de Administração, 78 alunos de Pedagogia, 65 alunos de Administração, 29 técnicos-administrativos, 5 terceirizados e 3 estagiários.

$\bigcirc$ período de aplicação da pesquisa foi iniciado em 21 de agosto de 2016 e finalizado em 15 de novembro de 2016 junto aos integrantes da amostra retornada da IES.

Um questionário de pesquisa para estar devidamente elaborado deve levar em consideração 2 (dois) aspectos muito importantes: a validade e a confiabilidade. A efetividade de um instrumento pode ser demonstrada pela sua validade. A validade indica que o instrumento mede o que pretende. Porém, para ser válido, o instrumento também deve ser confiável, ou seja, quando o resultado medido reflete o resultado verdadeiro (RICHARDSON, 1989; HAYES, 19981.

alfa de Cronbach é um dos mais aplicados instrumentos para mensurar a confiabilidade de instrumentos de pesquisa quantitativa, demonstrando a média das correlações entre os itens que fazem parte de um instrumento (STREINER, 2003), ou ainda, é uma medida pela qual algum constructo, conceito ou fator medido está presente em cada item que o explora (ROGERS, SHMITI, MULLINS, 2002).

Os valores apreciados para o coeficiente alfa de Cronbach são aqueles entre 0,80 e 0,90 para a consistência interna da escala, embora o valor mínimo aceitável seja 0,70 e acima de 0,90, pode-se considerar que há duplicidade e/ou redundância, ou seja, diversos itens estão medindo exatamente o mesmo elemento de um constructo e deveriam ser eliminados (STREINER, 2003).

$\bigcirc$ alfa de Cronbach do instrumento aplicado na presente pesquisa foi de 0,893, ficando no intervalo de aceitação da sua consistência interna. 


\section{Análise de dados e apresentação de resultados quantitativos}

A análise quantitativa das estruturas essenciais do conceito de autosustentabilidade organizacional (colaboradores, alunos e econômico-financeiro) considera os aspectos positivos e os aspectos de melhoria na IES do caso em estudo.

\section{Autossustentabilidade dos colaboradores}

Conforme o Gráfico 1, a seguir, essa estrutura demonstrou, na IES estudada, como aspectos com necessidade de melhoria: a remuneração dos colaboradores $(3,3)$; a segurança no trabalho $(3,3)$ e o reconhecimento dos colaboradores $(3,3)$. Aspecto apontado como mais positivo foi o relacionamento entre os colaboradores $(3,8)$.

\section{Gráfico 1}

\section{Autossustentabilidade Quantitativa dos Colaboradores}

40
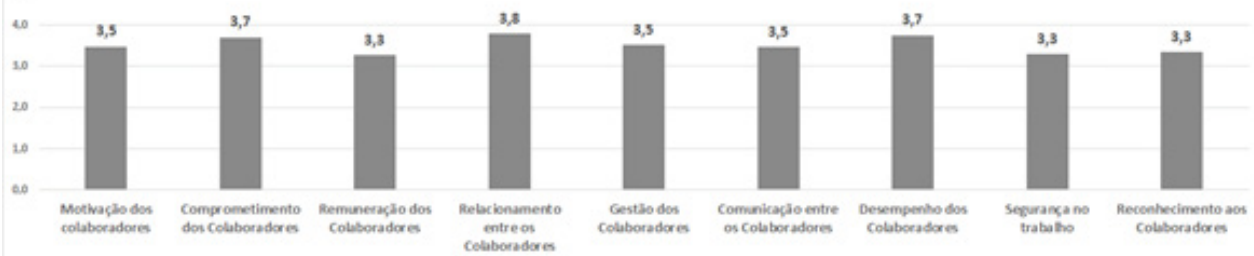

Fonte | Da pesquisa

Os resultados quantitativos, na estrutura colaboradores, aponta para a necessidade da gestão da IES focar ações sobre a remuneração e as formas de reconhecimento dos colaboradores (gestores, docentes, técnicos-administrativos, terceirizados e estagiários), bem como as condições ambientais e físicas de segurança para a realização do trabalho. Porém registra o relacionamento entre os colaboradores como fator positivo (ALDRICH; PFEFFER, 1976; PFEFFER; SALANCIK, 1978). 


\section{Autossustentabilidade dos alunos}

Os resultados obtidos na estrutura alunos, conforme o Gráfico 2, a seguir, teve como aspectos a serem melhorados: comunicação $(3,1)$; e preço $(3,1)$. $\bigcirc$ melhor aspecto citado foi a qualidade dos serviços educacionais $(3,7)$.

\section{Gráfico 2}

\section{Autossustentabilidade Quantitativa dos Alunos}

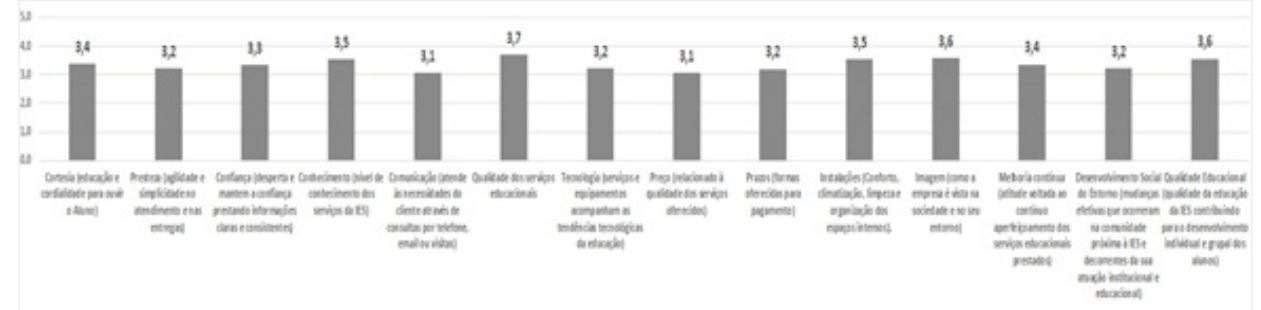

Fonte | Da pesquisa

Os resultados apresentados indicam a necessidade de melhor atendimento às necessidades dos alunos (comunicação) e uma melhor relação entre o preço e a qualidade dos serviços oferecidos, embora a qualidade dos serviços educacionais tenha sido destacada positivamente (HIT; IRELAND; HOSKISSON, 2008).

\section{Autossustentabilidade econômico-financeira}

Congregando as percepções dos respondentes, obteve-se como resultados na estrutura econômico-financeira, conforme o Gráfico 3, a seguir, como aspectos com necessidade de aprimoramento: as despesas totais da IES $(3,0)$ e as despesas específicas do curso de Pedagogia $(3,0)$. Como ponto satisfatório, foi destacada a receita do curso de Administração $(3,4)$. 


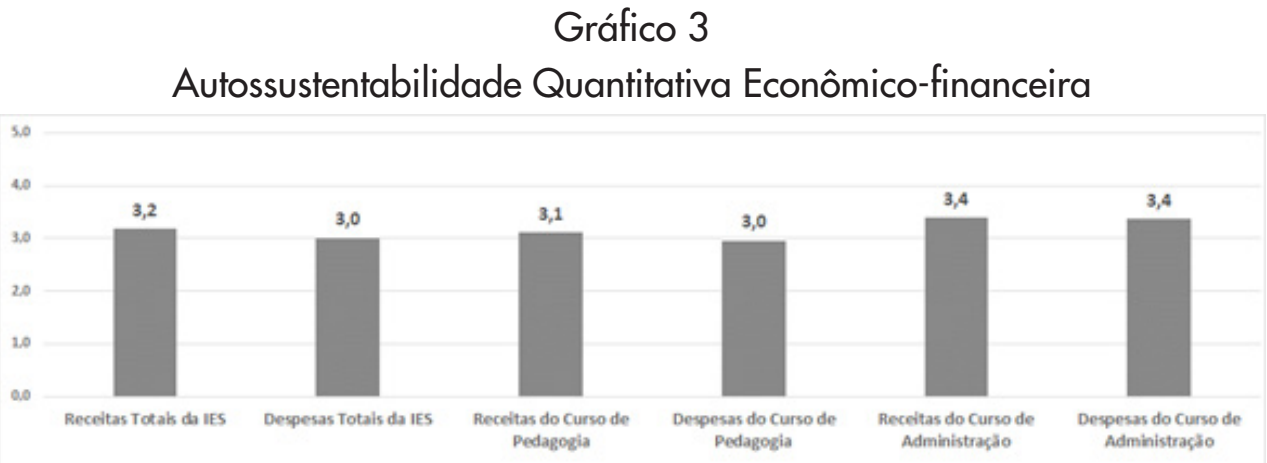

Fonte | Da pesquisa

A estrutura econômico-financeira prioriza as despesas institucionais e as despesas do curso de Pedagogia, bem como destaca positivamente as receitas do curso de Administração (ALDRICH; PFEFFER, 1976; PFEFFER; SALANCIK, 19781.

\section{Análise de dados e apresentação de resultados qualitativos}

A análise qualitativa das estruturas essenciais do conceito de autosustentabilidade organizacional (colaboradores, alunos e econômico-financeiro) considera os principais aspectos mais citados pelos respondentes.

\section{Autossustentabilidade dos colaboradores}

A Figura 3, a seguir, apresenta a rede de interesses produzida no software Atlas.ti7 7.1 para a estrutura colaboradores e na perspectiva dos técnicos-administrativos, dos docentes e dos alunos. 


\section{Figura 3}

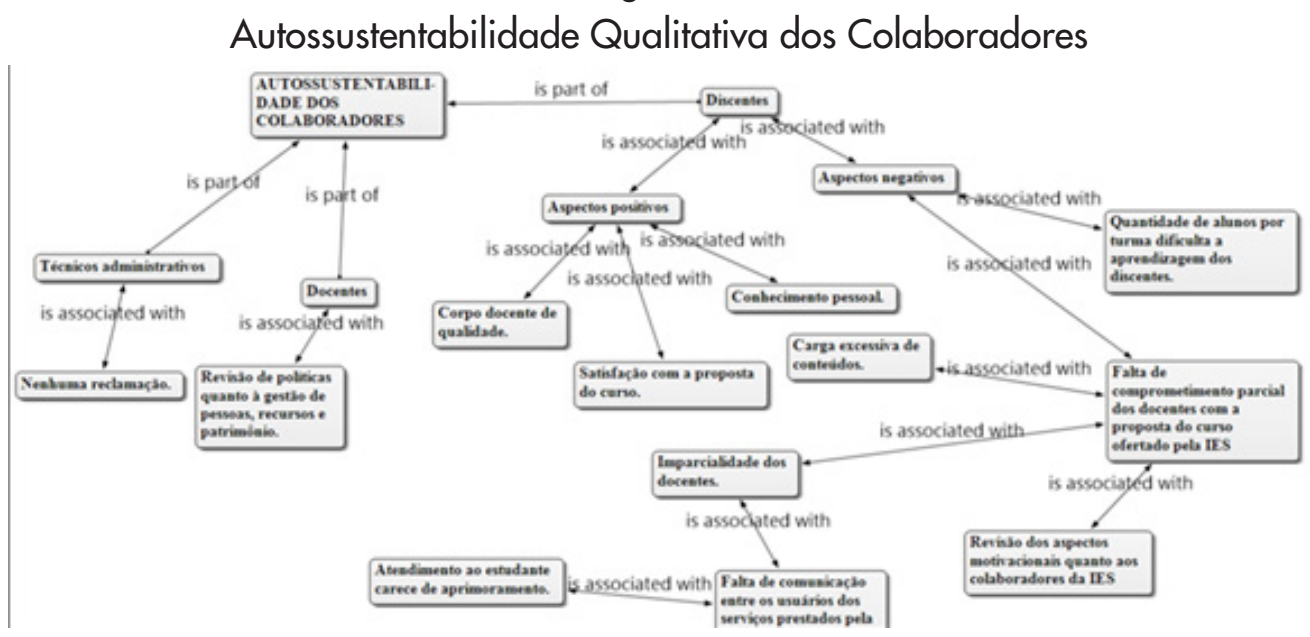

Fonte | Da pesquisa

Os técnicos-administrativos não se expressaram na parte qualitativa da pesquisa, deixando a reflexão da necessidade de aprofundamento no estudo. Os docentes apenas registraram a necessidade de revisão das políticas de gestão de pessoas na IES (ALDRICH; PFEFFER, 1976; PFEFFER; SALANCIK, 1978).

Já os alunos exploraram aspectos positivos e negativos. Entre os aspectos satisfatórios: corpo docente de qualidade; satisfação com a proposta do curso; e conhecimento pessoal. Como aspectos negativos: falta de comprometimento dos docentes com a proposta do curso; quantidade de alunos por turma; e revisão dos aspectos motivacionais dos colaboradores (HITT; IRELAND; HOSKISSON, 2008).

\section{Autossustentabilidade dos alunos}

A rede de interesses da estrutura alunos está configurada na Figura 3, a seguir, e apresenta os seguintes resultados, segundo os alunos de Pedagogia, os alunos de Administração e os técnicos-administrativos: 


\section{Figura 4}

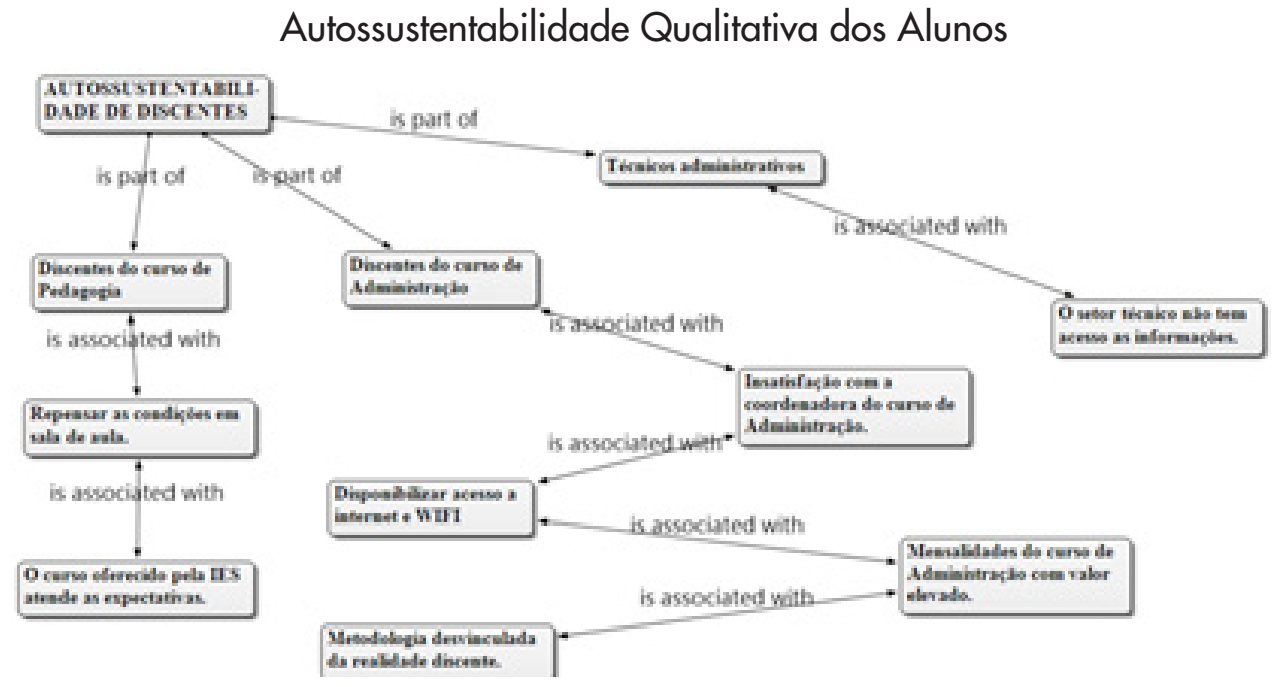

Fonte | Da pesquisa

Para os alunos de Pedagogia o curso atende às expectativas, 262 porém as condições de sala de aula precisam ser melhoradas. Os alunos de Administração registraram sua insatisfação com a coordenação do curso, a falta de acesso à internet/Wifi, o valor elevado da mensalidade e a metodologia desvinculada da realidade dos alunos (HITT; IRELAND; HOSKISSON, 2008).

Os técnicos-administrativos, por sua vez, afirmaram que não têm acesso às informações na IES (ALDRICH; PFEFFER, 1976; PFEFFER; SALANCIK, 1978).

\section{Autossustentabilidade econômico-financeira}

Na estrutura econômico-financeira, a morfologia da sua rede de interesses, conforme a Figura 3, a seguir, demonstra que a percepção dos alunos de Pedagogia aponta a necessidade de investimentos no curso, problemas financeiros com demissões de colaboradores, e o foco apenas no lucro financeiro. Os alunos de Administração registraram desinformações quanto às receitas e despesas da IES. Para os técnicos-administrativos, não fizeram nenhuma reclamação (HITT; IRELAND; HOSKISSON, 2008). 
Figura 5

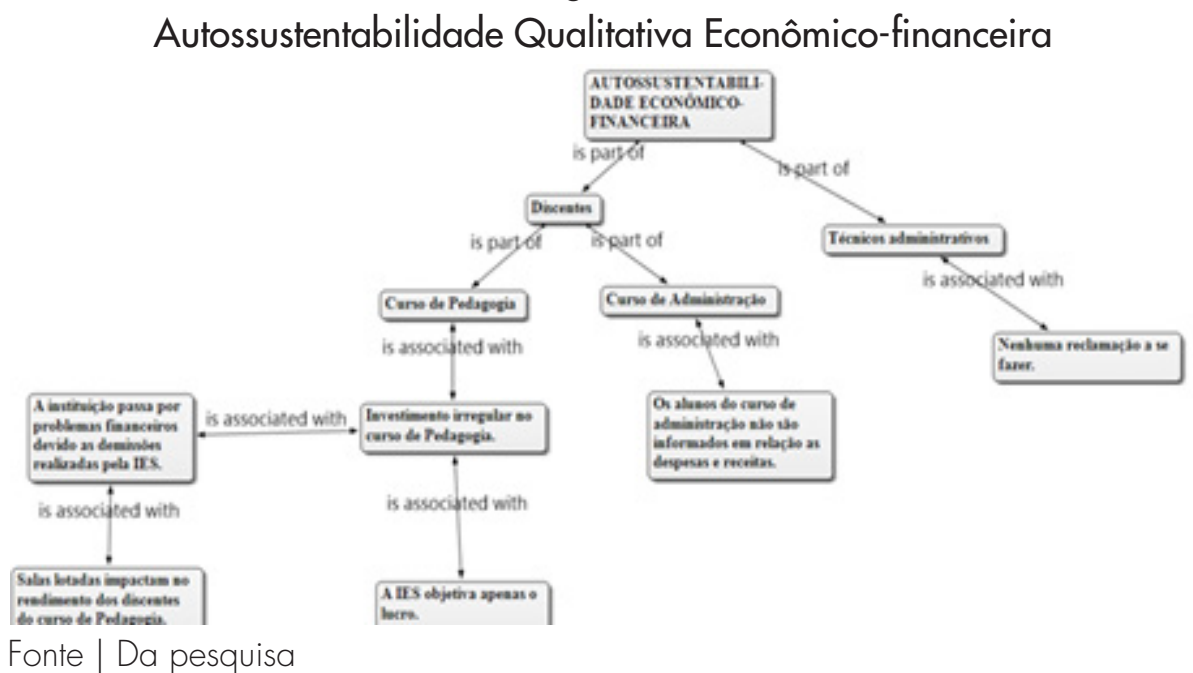

\section{Análise integrativa de dados}

esforço de integração entre as análises quantitativa e qualitativa permite visualizar as sintonias e as dissintonias entre os resultados alcançados com a pesquisa.

\section{Quadro 1}

Integração quantitativa e qualitativa dos resultados

\begin{tabular}{|c|c|}
\hline Resultados quantitativos & Resultados qualitativos \\
\hline \multicolumn{2}{|c|}{ Estrutura Colaboradores } \\
\hline $\begin{array}{l}\text { - A remuneração }(3,3) \text { e as formas de reco- } \\
\text { nhecimento }(3,3) \text { dos colaboradores carecem } \\
\text { de melhorias; } \\
\text { - As condições ambientais e físicas de segu- } \\
\text { rança do trabalho }(3,3) \text { com necessidade de } \\
\text { aprimoramentos; e } \\
\text { - O relacionamento entre os colaboradores } \\
(3,8) \text { como fator positivo. }\end{array}$ & $\begin{array}{l}\text { - As políticas de gestão de pessoas precisam } \\
\text { ser revisadas na IES. } \\
\text { - Revisão de elementos motivacionais para } \\
\text { os colaboradores. } \\
\text { - Quadro docente de qualidade, porém } \\
\text { com falta de comprometimento pleno com a } \\
\text { proposta do curso; e } \\
\text { - Satisfação dos alunos com a proposta do } \\
\text { curso, mas insatisfação com a elevada quan- } \\
\text { tidade de alunos por turma. }\end{array}$ \\
\hline
\end{tabular}


Avaliação e gestão da autossustentabilidade organizacional: estudo de caso em Faculdade Particular de Fortaleza-Ceará

\begin{tabular}{|c|c|}
\hline Resultados quantitativos & Resultados qualitativos \\
\hline \multicolumn{2}{|c|}{ Estrutura Alunos } \\
\hline $\begin{array}{l}\text { - A comunicação }(3,1) \text { na IES carece de } \\
\text { aperfeiçoamento; } \\
\text { - A relação entre o preço }(3,1) \text { e a qualidade } \\
\text { dos serviços oferecidos ainda é um desafio; e } \\
\text { - A qualidade dos serviços educacionais } \\
(3,7) \text { foi destacada positivamente }\end{array}$ & $\begin{array}{l}\text { - Os técnicos-administrativos não têm acesso } \\
\text { às informações na IES; } \\
\text { - A falta de acesso à internet/Wifi; } \\
\text { - Valor elevado da mensalidade; } \\
\text { - O curso de Pedagogia atende às expecta- } \\
\text { tivas dos alunos, porém as condições de sala } \\
\text { de aula precisam ser melhoradas; } \\
\text { - O curso de Administração não dispõe de } \\
\text { coordenação adequada; e } \\
\text { - A metodologia pedagógica precisa ser } \\
\text { vinculada à realidade dos alunos. }\end{array}$ \\
\hline \multicolumn{2}{|c|}{ Estrutura Econômico-financeira } \\
\hline $\begin{array}{l}\text { - As despesas institucionais }(3,0) \text { e as despe- } \\
\text { sas do curso de Pedagogia }(3,0) \text { precisam } \\
\text { ser melhor geridas; e } \\
\text { - As receitas do curso de Administração } \\
(3,4) \text { foram registradas positivamente. }\end{array}$ & $\begin{array}{l}\text { - Necessidade de investimentos no curso de } \\
\text { Pedagogia; } \\
\text { - A IES demonstrando problemas financeiros } \\
\text { com demissões de colaboradores; e } \\
\text { - Foco da IES apenas no lucro financeiro. }\end{array}$ \\
\hline
\end{tabular}

Fonte | Da pesquisa

A partir do Quadro 1 anterior, pode-se construir o Quadro 2, com as principais sintonias e dissintonias nos resultados quantitativos e qualitativos, alcançados com a pesquisa.

\section{Quadro 2}

\section{Sintonias e dissintonias de resultados}

\begin{tabular}{|l|l|}
\hline \multicolumn{1}{|c|}{ Sintonias } & \multicolumn{1}{|c|}{ Dissitonias } \\
\hline \multicolumn{1}{|c|}{ Estrutura Colaboradores } \\
\hline - A necessidade de revisão das políticas de & • O nível de comprometimento com a pro- \\
gestão de pessoas, envolvem como principais & posta curso é positivo para os alunos, mas \\
aspectos a remuneração, as formas de reco- & $\bullet$ quadro docente demonstra qualidade, \\
nhecimento, a motivação e a segurança do & mas também demonstra falta de comprometi- \\
traballho dos colaboradores; & mento pleno com a proposta do curso; \\
• O relacionamento interpessoal entre os cola- & $\bullet$ O nível de satisfação dos alunos é positivo \\
boradores não é desafio na IES. & com a proposta do curso, mas insatisfatória \\
& com a elevada quantidade de alunos por \\
& turma. \\
\hline
\end{tabular}




\begin{tabular}{|c|c|}
\hline Sintonias & Dissitonias \\
\hline \multicolumn{2}{|c|}{ Estrutura Alunoss } \\
\hline $\begin{array}{l}\text { - A comunicação na IES carece de aperfeiço- } \\
\text { amento. Comprovado com a falta de acesso } \\
\text { às informações por parte dos técnicos-admi- } \\
\text { nistrativos e com a falta de acesso à internet/ } \\
\text { Wifi; } \\
\text { - A percepção de valor elevado na mensa- } \\
\text { lidade cobrada, sintoniza-se com o desafio } \\
\text { na relação entre o preço e a qualidade dos } \\
\text { serviços oferecidos pela IES. }\end{array}$ & $\begin{array}{l}\text { - O curso de Pedagogia atende às expecta- } \\
\text { tivas dos alunos, porém as condições de sala } \\
\text { de aula precisam ser melhoradas; } \\
\text { - A metodologia pedagógica precisa ser } \\
\text { vinculada à realidade dos alunos, porém a } \\
\text { qualidade dos serviços educacionais foi des- } \\
\text { tacada positivamente. }\end{array}$ \\
\hline \multicolumn{2}{|c|}{ Estrutura Econômico-financeira } \\
\hline $\begin{array}{l}\text { - O nível elevado das despesas institucionais } \\
\text { e as efetivas demissões de colaboradores; } \\
\text { - As receitas satisfatórias do curso de } \\
\text { Administração e o foco da IES apenas no lu- } \\
\text { cro financeiro. }\end{array}$ & $\begin{array}{l}\text { - A necessidade de redução das despe- } \\
\text { sas e de maiores investimentos no curso de } \\
\text { Pedagogia. }\end{array}$ \\
\hline
\end{tabular}

Fonte | Da pesquisa

$\bigcirc$ mapeamento das principais sintonias e dissintonias entre os resultados alcançados com a pesquisa demonstram a necessidade de maior aprofundamento nos pontos, visando melhorar o entendimento desses fenômenos institucionais e seus desdobramentos e relações com outros fatores que podem promover a autosustentabilidade organizacional.

\section{Considerações finais}

A expansão das IES privadas é resultante da aplicação de políiticas educacionais neoliberais consolidadas na década de 1990 com a parceria de instituições internacionais, valorizando o "serviço educacional" por instituições privadas.

O estudo de caso quali-quantitativo realizado em IES particular de Fortaleza-Ceará, a partir da aplicação de um questionário com questões objetivas e abertas, junto a gestores, docentes, técnicos, terceirizados e estagiários; e a discentes dos 2 (dois) cursos pesquisados visando à avaliação da sua gestão da autossustentabilidade organizacional, demonstrou-se viável de empreendimento. 
As questões norteadores da problemática da pesquisa foram respondidas, já que as propostas de avaliação estrutural-sistêmica no campo da Educação, e das teorias administrativas da dependência de recursos e da visão baseada em recursos (VBR) se apresentam viáveis para fundamentação do conceito de autossustentabilidade organizacional em IES particulares, bem como o conceito de tríade da autossustentabilidade organizacional (colaboradores; alunos; e econômico-financeirol pode ser aplicado e de que forma na avaliação e na gestão de IES privada.

O objetivo central foi plenamente atingido, pois o estudo de caso em IES particular de Fortaleza-Ceará que oferta cursos presenciais de graduação em Administração e Pedagogia, permitiu aplicar modelo para avaliar a gestão da autossustentabilidade organizacional, baseada nas suas estruturas essenciais.

Os objetivos específicos pretendidos também foram alcançados com a aplicação da estratégia metodológica quatripolar de De Bruyne; Herman; De Schoutheete (1977) e na investigação dos principais recursos aplicados na gestão da autossustentabilidade organizacional (colaboradores, alunos e econômico-financeira).

Os principais resultados na avaliação da gestão da estrutura colaboradores foram a constatação da revisão das políticas de gestão de pessoas, envolvendo os aspectos da remuneração, das formas de reconhecimento, da motivação e da segurança do trabalho dos colaboradores.

A estrutura alunos apresentou os seguintes principais resultados: a necessidade de aprimoramento da comunicação nos ambientes da IES; a percepção de valor elevado na mensalidade cobrada, e a dificuldade de entendimento da relação entre o preço e a qualidade dos serviços oferecidos pela IES.

Os principais resultados apresentados para a estrutura econômico-financeira sinalizam o nível elevado das despesas institucionais, as receitas satisfatórias do curso de Administração e a percepção do foco da IES apenas no lucro financeiro.

Em uma síntese das conclusões, vê-se, na abordagem quantitativa da pesquisa, a ordem de satisfação dos respondentes com as estruturas essenciais de autosustentabilidade: colaboradores $(3,5)$, alunos $(3,4)$ e econômico-financeira $(3,2)$. 
Na sua vertente qualitativa, a ordem de indicações de problemas nas estruturas essenciais de autosustentabilidade foi a seguinte: alunos com 9 aspectos levantados sem repetições; colaboradores com 7; e econômico-financeiro com 5 indicações de necessidades de melhorias.

Conclui-se que a estrutura econômico-financeira apresenta a pior avaliação quantitativa, sintonizada com o momento atual da economia brasileira e cearense, com aumento da evasão e da inadimplência e redução de matrículas nas IES particulares.

Na avaliação qualitativa, a dimensão de maior lista de problemas foi a estrutura essencial alunos, demonstrando a extrema necessidade de valorização da qualidade educacional junto aos principais beneficiários da educação.

Entre as dissintonias (divergências) encontradas na pesquisa, elencam-se como principais resultados: (1) O nível de comprometimento com a proposta do curso é positivo para os alunos, mas negativa por parte dos docentes, apesar de esses terem qualidade de conteúdo; (2) $\bigcirc$ nível de satisfação dos alunos é positivo com a proposta do curso, mas insatisfatória com a elevada quantidade de alunos por turma; (3) $\bigcirc$ curso de Pedagogia atende às expectativas dos alunos, porém as condições de infraestrutura ainda carecem de melhorias; (4) A metodologia pedagógica aplicada pelos docentes precisa ser vinculada à realidade dos alunos, porém a qualidade dos serviços educacionais foi destacada como positiva; (5) A necessidade de redução das despesas e, ao mesmo tempo, a carência de investimentos no curso de Pedagogia.

Embora as IES particulares ainda não sejam alvo de maior interesse nas pesquisas em Educação e Administração, devido às dificuldades de acesso a informações motivadas pela concorrência, no caso em estudo também foram percebidas algumas resistências da parte de gestores, docentes e técnicos-administrativos. Mesmo assim, os resultados da pesquisa foram devolvidos para a IES, por meio de relatório síntese, demonstrando a avaliação da gestão da autosustentabilidade organizacional.

A análise integrada da pesquisa quantitativa e qualitativa gerou sintonias e dissintonias para os seus resultados, indicando a necessidade de maior aprofundamento na sua parte qualitativa, com emprego de técnicas que verticalizem a obtenção de dados, como grupos focais e entrevistas narrativas, permitindo resultados ainda mais consistentes. 


\section{Referências}

ALDRICH, Howard E.; PFEFFER, Jeffrey. Organizations and envioronments. Ithaca: New Uork State School of Industrial and Labor Relations, Cornell University, 1976.

BACHELARD, Gaston. O novo espírito científico. Tradução Juvenal Hahne Júnior. Rio de Janeiro: Tempo Brasileiro, 1968.

A formação do espírito científico: contribuição para uma psicanálise do conhecimento. Tradução Estela dos Santos Abreu. Rio de Janeiro: Contraponto, 1996.

BRASIL. Lei n 9.394, de 20 de dezembro de 1996. Estabelece as Diretrizes e Bases da Educação Nacional. Diário Oficial [da] União da República Federativa do Brasil, Brasília, 23 dez. 1996.

BRASIL. Instituto Nacional de Estudos e Pesquisas Educacionais "Anísio Teixeira". Censo da Educação Superior 2013. Brasília: Inep/Mec, 2015. Disponível em: http://download. inep.gov.br/educacao_superior/censo_superior/apresentacao/2014/coletiva_censo_ superior_2013.pdf. Acesso em: 29 out. 2015.

CABRAL NETO, Antônio; RODRIGUEZ, Jorge. Reformas educacionais na América Latina: 268 cenários, proposições e resultados. In: CABRAL NETO, Antônio; CASTRO, Alda Maria Duarte Araújo; FRANÇA, Magna; QUEIROZ, Maria Aparecida de (Org.). Pontos e contrapontos da política educacional: uma leitura contextualizada de iniciativas governamentais. Brasília: Líber Livro, 2007.

BARBALHO, Maria Goretti Cabral. A educação superior: tendências e estratégias de expansão na América Latina e no Brasil. In: CABRAL NETO, Antônio; CASTRO, Alda Maria Duarte Araúio; FRANÇA, Magna; QUEIROZ, Maria Aparecida de (Org.). Pontos e contrapontos da política educacional: uma leitura contextualizada de iniciativas governamentais. Brasília: Líber Livro, 2007.

DE BRUYNE, Paul; HERMAN Jacques; DE SCHOUTHEETE, Marc. Dinâmica da pesquisa em ciências sociais: os polos da prática metodológica. Tradução Ruth Joffily. Rio de Janeiro: Francisco Alves, 1977.

FAVERO, Maria de Lourdes A.; SGUISSARDI, Waldemar. Quantidade/qualidade e educação superior. Revista Educação em Questão, Natal, v. 42, n. 29, p. 61-88, jan./abr. 2012.

HAYES, Bob E. Measuring customer satisfaction: survey design, use, and statistical analysis methods. Milwaukee, Wisconsin: ASQC Quality Press, 1998. 
HITT, Michael A.; IRELAND, R. Duarte; HOSKISSON, Robert E. Administração estratégica: competitividade e globalização. 2. ed. Tradução AllTasks. São Paulo: Thomson Learning, 2008.

LIMA, Marcos Antonio Martins. Autoavaliação e desenvolvimento institucional na educação superior: projeto aplicado em cursos de Administração. Fortaleza: Edições UFC, 2008.

LUCK, Heloísa. Gestão educacional: uma questão paradigmática. 2. ed. Petrópolis: Vozes, 2006.

PFEFFER, Jeffrey; SALANCIK, Gerald. The external control of organizations: a resource dependence perspective. New York: Harper \& Row, 1978.

RICHARDSON, R. J. Pesquisa social, métodos e técnicas. 2. ed. São Paulo: Atlas, 1989.

ROGERS, William; SCHIMITI, Neal; MULLINS, Morell. Correction for unreliability of multifactor measures: comparison of Alpha and parallel forms approaches. Organizational Research Methods, v. 5, p. 184-199, $1^{\circ}$ apr. 2002.

SAMPAIO, Helena Maria Sant'Ana. O ensino superior no Brasil: o setor privado. São Paulo: Hucitec/FAPESP, 2000. (Estudos Brasileiros, 34).

SANDER, Benno. Administração da educação no Brasil: genealogia do conhecimento. Brasilia: Liber Livro. 2007.

SAVIANI, Dermeval. Educação: do senso comum à consciência filosófica. 4. ed. São Paulo: Cortez/Autores Associados, 1984.

SOUZA, Paulo Nathanael Pereira de. LDB e educação superior: estrutura e funcionamento. 2. ed. São Paulo: Pioneira Thompson Learning. 2001.

STREINER, David. Being inconsistent about consistency: when coefficient alpha does and doesn't matter. Journal of Personality Assessment, v. 80, n. 3, p. 217-222, jun. 2003.

VAHL, Teodoro Rogério. A privatização do ensino superior no Brasil: causas e conseqüências. Florianópolis: Editora UFSC, 1980.

Prof. Dr. Marcos Antonio Martins Lima Universidade Federal do Ceará Faculdade de Educação Departamento de Fundamentos da Educação 
Programa de Pós-Graduação em Educação Grupo de Pesquisa de Avaliação em Gestão Educacional | GPAGE E-mail | marcos.a.lima@terra.com.br

Prof. Dr. Antonio Cabral Neto Universidade Federal do Rio Grande do Norte Departamento de Fundamentos e Políticas da Educação Programa de Pós-Graduação em Educação Grupo de Pesquisa Educação, Política e Práxis Educativas

E-mail|cabraln@ufrnet.br

Recebido 31 out. 2016 Aceito 13 fez. 2017 